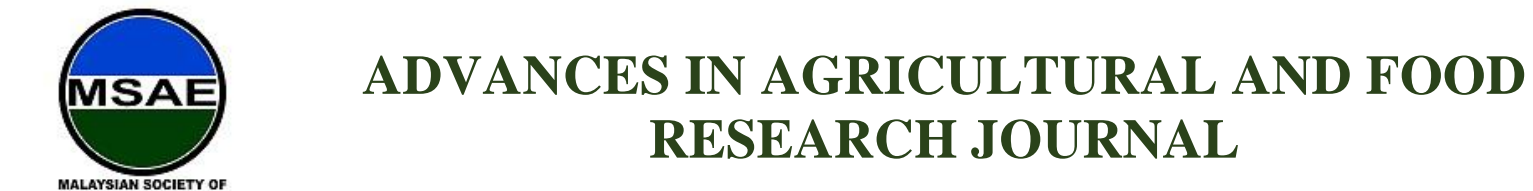

Original Research Article

\title{
Physical Properties of Different Local Glutinous Rice Cultivar (Susu and Siding) and Commercial Thai Cultivar (Susu)
}

\author{
Norzahirah Zainal ${ }^{1}$, Rosnah Shamsudin ${ }^{1 *}$ \\ ${ }^{1}$ Department of Process and Food Engineering, Faculty of Engineering, Universiti Putra Malaysia, 43400 \\ Serdang, Selangor, Malaysia \\ *Corresponding author: Rosnah Shamsudin, Department of Process and Food Engineering, Faculty of \\ Engineering, Universiti Putra Malaysia, 43400 Serdang, Selangor, Malaysia; rosnahs@upm.edu.my
}

\begin{abstract}
Glutinous rice (Oryza sativa var. glutinosa) is known as waxy rice or sticky rice and it has an opaque and small size grain cultivar distinct from common white rice. In outlining the equipment for processing, storage, sorting, sizing and other post-harvest equipment, the physical properties are very important. Two different cultivars of Malaysian local glutinous rice known as Susu and Siding were evaluated in this study. The objective of this study is to compare the physical properties of two different local cultivars in designing the rice processing equipment. For Susu cultivar, the average of length, width and thickness were $6.63 \mathrm{~mm}, 1.88 \mathrm{~mm}$ and $1.50 \mathrm{~mm}$, respectively. The corresponding values were 6.24 $\mathrm{mm}, 1.98 \mathrm{~mm}$ and $1.48 \mathrm{~mm}$ for Siding cultivar. For Susu cultivar, the average of aspect ratio, sphericity, volume, surface area, bulk density, true density, porosity, 1000 weight kernel and angle of repose were $0.28,0.40 \%, 9.81 \mathrm{~mm}^{3}, 19.02 \mathrm{~mm}^{2}, 800.54 \mathrm{~kg} / \mathrm{m}^{3}, 1500.36 \mathrm{~kg} / \mathrm{m}^{3}$, $46.65 \%, 18.88 \mathrm{~g}$ and $39.45^{\circ}$, respectively. The corresponding values were $0.32,0.42 \%, 10.25$ $\mathrm{mm}^{3}, 19.45 \mathrm{~mm}^{2}, 772.73 \mathrm{~kg} / \mathrm{m}^{3}, 1229.51 \mathrm{~kg} / \mathrm{m}^{3}, 37.15 \%, 17.04 \mathrm{~g}$ and $40.08^{\circ}$ for Siding cultivar. The physical properties of the same cultivar ( $\mathrm{Susu}$ ) showed no significant difference, but apparently Siding was higher in bulk density, which requires a larger-sized silo compared to Susu cultivar in term of equipment design.
\end{abstract}

Keywords: Glutinous rice; physical properties; Susu; Siding; Susu Thai

Received: $6^{\text {th }}$ June 2020

Received in revised form: $14^{\text {th }}$ October 2020

Citation: Zainal N. and Shamsudin R. Physical properties of different local glutinous rice cultivar

Accepted: $30^{\text {th }}$ December 2020

Available Online: $24^{\text {th }}$ January 2021 (Susu and Siding) and commercial Thai cultivar (Susu). Adv Agri Food Res J 2021; 2(1): a0000178. https://doi.org/10.36877/aafrj.a0000178

\section{Introduction}

Rice (Oryza sativa L.) is one of the leading food crops in the world and is the staple food of more than half of the world's population. Food Agriculture Organization (FAO) (2018) stated global consumption of rice has been slightly increasing to 490.27 million 
metric tonnes from 437.18 million metric tonnes in 2008. Thousands of rice cultivars are available throughout the world and glutinous rice (Oryza sativa var. glutinosa) is one of the most popular known cultivars, commonly known as sticky rice or waxy rice. In Malaysia, during the Malay festive seasons, the glutinous rice is very high in demand. It can be divided into short- or long- grained rice that are sticky when being cooked. Different type of cultivars are being aggressively demanded by the fellow consumers in improving the quality, acceptability and marketability of the particular rice cultivar. While, for designing and outlining an appropriate machinery for grain-processing operations such as sorting, drying, threshing, milling and optimization catered for each specific cultivar are probably relied on the information and knowledge towards the physical properties of rice grain materials (Mir et al., 2013).

Nowadays, Malaysia only imports the glutinous rice from Thailand. According to the Global Agricultural Information Network (2017), about 15\% of glutinous rice has been imported out of 891,000 metric tonnes of total rice imported into Malaysia. Therefore, since Langkawi Island is consistently hot and humid every year, Langkawi has the potential to become one of the local glutinous rice producers. Thai glutinous rice is popular in Malaysia, since Malaysia has stopped cultivated them in the 1980's. This can be proven by the Malaysian Agricultural Research and Development Institute (MARDI) research (Husain, 1984). In comparison to Susu Thai cultivar, Thailand and Langkawi Island have a quite similar conducive weather and both situated at the northern Malaysia region. On the other hand, the area of plantation for both local cultivars are planted about 14.76 ha and 24.2 ha for Susu and Siding, respectively in Langkawi Island. By physical appearance, Susu cultivar is easier to be differentiated in comparison to Siding. The Susu cultivar is significant by the size of the leaves, which is much wider than Siding. Moreover, Susu cultivar seed is germinated on the top of their leaves, while Siding cultivar seed is germinated below their leaves.

The prior properties of grain are meant to be their physical properties or characteristics. Solutions to problems in the post-harvest process include knowledge of their engineering and physical properties (Irtawange, 2000). During fabrication of bulk storage facilities and the calculation of the dimensions of intermediate holding bins of a given capacity in a mill, these two properties are significant. Surface area and volume of the kernels can be calculated, since they are essential for modelling in drying process, aeration, heating and cooling process. Grain size and shape are the prior quality criteria in developing 
rice cultivars for commercial production. They are primary factors in marketing, grading and processing (Singh et al., 2005).

Sizing grain hoppers and storage facilities are helpful by determining the bulk density, true density and porousity (the ratio of inter granular space to the total space occupied by the grain). The condition and design of storage facilities can affect the rate of heat and mass transfer of moisture during aeration and drying processes. Grain bed with low porousity will have a greater resistance to water vapour escape, during the drying process, in which this may cause high electrical power to drive the aeration fans.

Rice cannot be considered to have uniform properties, since grain property variation is wide when considering different cultivars. Remarkable variation in the processing quality of the grain is a result from differences in grain properties. Therefore, the aim of this study is to determine the physical properties such as dimension, shape, bulk density, true density, porosity, sphericity, 1000 weight kernel and angle of repose of different cultivars of local glutinous rice kernel (Susu and Siding) with Susu Thai glutinous rice, act as reference, which can facilitate in the plan or design of processing, handling and processing for rice yield.

\section{Materials and Methods}

\subsection{Rice Sample}

Local glutinous rice kernel from Susu cultivar was chosen from a rice plantation at the Langkawi Island and Siding from a plantation in Kedah, while commercial glutinous rice kernel from Thailand, Susu cultivar, was used as a reference. Both local Susu and Siding cultivars' grains were cleaned and milled by Padiberas Nasional Berhad (BERNAS).

\subsection{Grain Shape and Dimension}

There are three principal dimensions of the grains: length (l), width (w), and thickness ( $\mathrm{t}$ ) were required to be determined and characterised. These measurements were recorded by using Vernier caliper to an accuracy of $0.05 \mathrm{~mm}$. 20 grains of milled rice from each sample were collected at random and the dimensions were measured to obtain the average length (1) in millimeter (mm), width (w) in $\mathrm{mm}$, breadth (b) in $\mathrm{mm}$, and thickness (t) in $\mathrm{mm}$. Figure 1 shows the measurement of grain dimension of rice. 


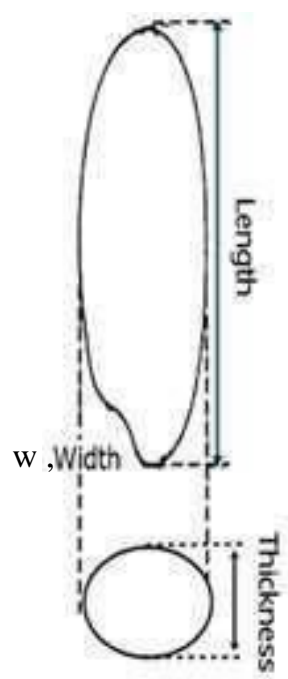

Figure 1. Dimension of rice grain.

\subsection{Weight Kernel}

The 1000 weight kernel of each sample were counted randomly in triplicate and weighed separately to determine 1000 kernel weight by weighing them onto the analytical balance (Singh et al., 2003).

\subsection{Surface Area, Aspect Ratio and Sphericity}

The surface area $(\mathrm{S})$ in $\mathrm{mm}^{2}$, aspect ratio $\left(\mathrm{R}_{\mathrm{a}}\right)$ unitless, and sphericity $(\emptyset)$ in unit $\%$ of rice was determined by measurement of the grain dimension. All of the properties were calculated as follows (Jain \& Bal, 1997):

$$
\begin{aligned}
& S=\frac{\pi b l^{2}}{(2 l-b)} \\
& \text { Where } \quad \mathrm{b}=\sqrt{w t} \\
& \mathrm{R}_{\mathrm{a}}=\frac{\mathrm{w}}{\mathrm{l}} \\
& \emptyset=\frac{(\mathrm{lwt})^{1 / 3}}{\mathrm{l}}
\end{aligned}
$$

\subsection{Bulk Density, True Density and Porousity}

Grain volume (V) in unit $\mathrm{mm}^{3}$ were calculated by using formula (Jain \& Bal,1997) below: 


$$
V=0.25\left[\left(\frac{\pi}{6}\right) l(w+t)^{2}\right]
$$

The bulk density $(\rho b)$ in unit $\mathrm{kg} / \mathrm{m}^{3}$ was computed when rice was filled into $100 \mathrm{ml}$ beaker and then mass of the rice grain $\left(\mathrm{Mg}_{\mathrm{g}}\right)$ was weighed. The weight of the rice was divided with the volume of the beaker $\left(\mathrm{V}_{\mathrm{b}}\right)$ (i.e. $\left.100 \mathrm{ml}\right)$. The same procedure was repeated for five times (Fraser et al., 1978). The formula for bulk density is stated as below:

$$
\rho_{\mathrm{b}}=\frac{\mathrm{M}_{\mathrm{g}}}{\mathrm{V}_{\mathrm{b}}}
$$

The true density $(\rho t)$ in unit $\mathrm{kg} / \mathrm{m}^{3}$ was computed by pouring $50 \mathrm{ml}$ of distilled water into the $100 \mathrm{ml}$ beaker and then adding $3 \mathrm{~g}$ sample of rice. The water displacement $\left(\mathrm{V}_{\mathrm{dw}}\right)$ by rice was recorded. The measurement was replicated five times (Shittu et al., 2012):

$$
\rho_{\mathrm{t}}=\frac{\mathrm{M}_{\mathrm{gt}}}{\mathrm{V}_{\mathrm{dw}}}
$$

The porousity $(\varepsilon)$ in unit \% determination is based on the bulk density and true density of the rice grain. The porousity of rice grain was calculated by using the following formula (Jain \& Bal, 1997):

$$
\varepsilon=\frac{\rho_{t}-\rho_{b}}{\rho_{t}} \times 100
$$

\subsection{Angle of Repose}

Angle of repose is a parameter that measured the ability of material to stand, when heaped, whereby the granular material steepest angle of descent or dip is relative to the horizontal plane. This was determined by using the apparatus consisting of a plywood box of $140 \times 160 \times 35 \mathrm{~mm}$ and two plates: fixed and adjustable. The box was filled with the sample, and then the adjustable plate was inclined gradually allowing the seeds to follow and assuming a natural slope, this was measured as emptying angle of repose (Tabatabaeefar, 2003). 


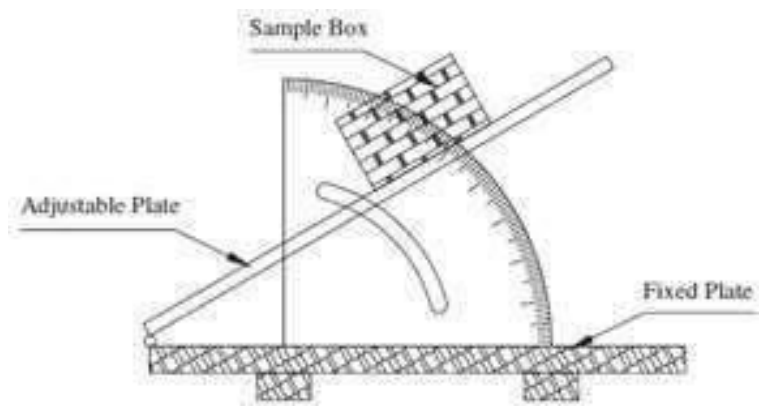

Figure 2. Apparatus for measuring emptying angle of repose.

\section{Results}

\subsection{Physical Properties of Susu and Siding Cultivar}

Table 1 shows a summary of the physical properties of local Susu and local Siding.

The Susu Thai cultivar is act as a reference.

Table 1. Average value of physical properties: Different glutinous rice cultivars

\begin{tabular}{|c|c|c|c|}
\hline \multirow{2}{*}{ Properties } & \multicolumn{3}{|c|}{ Grain/Rice cultivar } \\
\hline & $\begin{array}{l}\text { Susu Thai } \\
\text { (reference) }\end{array}$ & Local Susu & Local Siding \\
\hline Length (mm) & $6.57 \pm 0.28^{\mathrm{a}}$ & $6.63 \pm 0.24^{\mathrm{a}}$ & $6.24 \pm 0.42^{\mathrm{b}}$ \\
\hline Width (mm) & $1.98 \pm 0.09^{\mathrm{b}}$ & $1.88 \pm 0.10^{\mathrm{a}}$ & $1.98 \pm 0.08^{\mathrm{b}}$ \\
\hline Thickness (mm) & $1.47 \pm 0.09^{\mathrm{a}}$ & $1.50 \pm 0.07^{\mathrm{c}}$ & $1.48 \pm 0.10^{\mathrm{a}}$ \\
\hline Aspect ratio & $0.30 \pm 0.02^{\mathrm{a}}$ & $0.28 \pm 0.02^{\mathrm{a}}$ & $0.32 \pm 0.03^{\mathrm{a}}$ \\
\hline $\mathrm{L} / \mathrm{B}$ ratio & $3.58 \pm 0.34^{\mathrm{a}}$ & $3.82 \pm 0.06^{\mathrm{a}}$ & $3.17 \pm 0.06^{\mathrm{a}}$ \\
\hline Sphericity (\%) & $0.41 \pm 0.01^{\mathrm{a}}$ & $0.40 \pm 0.01^{\mathrm{a}}$ & $0.42 \pm 0.02^{\mathrm{a}}$ \\
\hline Volume $\left(\mathrm{mm}^{3}\right)$ & $10.25 \pm 0.10^{\mathrm{a}}$ & $9.81 \pm 1.15^{\mathrm{a}}$ & $9.87 \pm 0.93^{\mathrm{b}}$ \\
\hline Surface area $\left(\mathrm{mm}^{2}\right)$ & $20.22 \pm 1.36^{\mathrm{c}}$ & $19.02 \pm 4.31^{\mathrm{a}}$ & $19.45 \pm 1.73^{b}$ \\
\hline Bulk density $\left(\mathrm{kg} / \mathrm{m}^{3}\right)$ & $767.22 \pm 1.59^{\mathrm{a}}$ & $800.54 \pm 1.20^{\mathrm{a}}$ & $772.73 \pm 1.28^{\mathrm{a}}$ \\
\hline True density $\left(\mathrm{kg} / \mathrm{m}^{3}\right)$ & $1206.23 \pm 3.89^{\mathrm{a}}$ & $1500.36 \pm 6.98^{\mathrm{a}}$ & $1229.51 \pm 26.86^{b}$ \\
\hline Porosity $(\%)$ & $36.40 \pm 2.15^{\mathrm{a}}$ & $46.65 \pm 2.40^{\mathrm{c}}$ & $37.15 \pm 2.20^{\mathrm{b}}$ \\
\hline $\begin{array}{l}10000 \text { weight kernel } \\
(\mathrm{g})\end{array}$ & $17.93 \pm 0.15^{\mathrm{a}}$ & $18.88 \pm 0.10^{\mathrm{a}}$ & $17.04 \pm 0.20^{\mathrm{b}}$ \\
\hline $\begin{array}{l}\text { Angle of repose } \\
\text { (deg.) }\end{array}$ & $40.08^{\circ} \pm 1.05^{\mathrm{a}}$ & $39.45^{\circ} \pm 1.03^{\mathrm{a}}$ & $38.85^{\circ} \pm 0.95^{\mathrm{a}}$ \\
\hline
\end{tabular}

Mean $( \pm \mathrm{SD})$ with the same letter in the same row do not differ significantly $(P>0.05)$

Length, width and thickness determine the rice grain's dimension. Based on Table 1, length of Susu Thai and local Susu did not show a remarkable contrast between them, but, significantly longer than local Siding cultivar. At 5\% level of likelihood, it shows no notable 
differences for width and thickness between Susu Thai and Siding cultivar. However, it shows significant differences to the local Susu cultivar. The average value of length, width and thickness for local Susu cultivar were found to be $6.63 \mathrm{~mm}, 1.88 \mathrm{~mm}$ and $1.50 \mathrm{~mm}$, respectively, while $6.24 \mathrm{~mm}, 1.98 \mathrm{~mm}$ and $1.48 \mathrm{~mm}$ were obtained for Siding cultivar. In comparison, Susu Thai resulted to $6.57 \mathrm{~mm}, 1.98 \mathrm{~mm}$ and $1.47 \mathrm{~mm}$, respectively, for its length, width and thickness. Susu Thai and local Siding cultivars were wider compared to local Susu. However, local Susu cultivar was thicker than Susu Thai and local Siding cultivars. Length of local Susu cultivar similar to the length of Pulut Malaysia I cultivar, which was $6.64 \mathrm{~mm}$ as per reported by Husain (1984). The length-breadth (L/B) ratio for three of the rice cultivars did not present significant differences. The $\mathrm{L} / \mathrm{B}$ ratio mean value for Susu Thai, local Susu and local Siding were 3.58, 3.82 and 3.17, respectively. A length to breadth ratio of above 3 is considered as slender (IRRI, 1980). For the local cultivars, both of the seeds can be considered as slender. However, the control sample has the highest L/B ratio, which yielded very significant slender shape grains. L/B ratio shows the dimension of rice grain. This proves that the dimension for different cultivar is similar, since they were from the same glutinous rice type.

\subsection{Weight Kernel}

At the 5\% level of probability, the 1000 weight kernel of the local Susu and Susu Thai cultivars did not present a remarkable contrast. Both cultivars showed higher 1000 weight kernel than local Siding cultivar. Local Susu showed an average of 1000 weight kernel of $18.88 \mathrm{~g}$ against $17.93 \mathrm{~g}$ and $17.04 \mathrm{~g}$, respectively, for Susu Thai and local Siding. To measure the correlative amount of foreign substance in a designated bulk of raw rice and the number of shrink or unripe kernels, normally it is based on the index of milling outturn. So, 1000 grain weight of rice is very crucial in this study (Luh, 1980).

\subsection{Surface Area, Aspect Ratio and Sphericity}

Surface area and volume are two good parameters to be considered in designing the drying system for these glutinous rice. The result for surface area for Susu Thai, local Susu and local Siding were $20.22 \mathrm{~mm}^{2}, 19.02 \mathrm{~mm}^{2}$ and $19.45 \mathrm{~mm}^{2}$ respectively. These three cultivars showed remarkable contrasts of surface area values. The grain volume showed significant differences between both Susu cultivar and Siding cultivar. The average volume values for Susu Thai, local Susu and local Siding were $10.25 \mathrm{~mm}^{3}, 9.81 \mathrm{~mm}^{3}$ and $9.87 \mathrm{~mm}^{3}$, respectively. Surface area of the grain positively correlated with the volume of the grain. Heat transfer surface importantly influenced the rate or speed of heat transfer or heat exchange within the material. Higher rate of heat transfer occurs when the material has smaller volume per unit surface contact (Varnamkhasti et al., 2008). In this study, Susu Thai has the highest rate of heat transfer, hence resulted to shorterdrying time. Also, sphericity 
for the rice grains poorly showed remarkable differences between cultivars. The sphericity ranges from $0.40 \%-0.42 \%$. For many agricultural materials, raw rough rice falls within ranges from 0.32 to $1 \%$ for the sphericity values (Mohsenin, 2001). Thus, result from these three cultivars complied greatly with the previous finding.

\subsection{Bulk Density, True Density and Porousity}

At the $5 \%$ probability, bulk density values showed no remarkable contrast between three cultivars, regardless of being local or commercial rice. In the existing grain of a combined hopper, the design needs to ascertain the volume. So, various approaches were applied in this agricultural industry. Information about bulk density is useful in controlling the load of product in the hopper. The bulk density mean values for local Susu and local Siding were $800.54 \mathrm{~kg} / \mathrm{m}^{3}$ and $772.73 \mathrm{~kg} / \mathrm{m}^{3}$, respectively. Compared to Susu Thai cultivar, the mean value bulk density was $767.22 \mathrm{~kg} / \mathrm{m}^{3}$. In outlining the storage bins and silos design, bulk density is useful in this application (Nalladulai et al., 2002). Due to the bulk density value for Siding was slightly smaller than Susu cultivar, Siding needs a bigger silo compared to Susu cultivar, in relation to the same load of rice kernels.

Then, the true density of local Siding showed a significant difference between Susu Thai and local Susu cultivars. The mean value of true density for Susu Thai, local Susu and local Siding were found to be $1206.23 \mathrm{~kg} / \mathrm{m}^{3}, 1500.36 \mathrm{~kg} / \mathrm{m}^{3}$ and $1229.51 \mathrm{~kg} / \mathrm{m}^{3}$, respectively. To segregate seeds of cereal crops by true density, pneumatic sorting tables were used. The porousity values for three difference cultivars showed notable differences at the $5 \%$ probability level. The corresponding mean value for local Susu porousity was $46.65 \%$ higher than Susu Thai and local Siding, which was found to be $36.40 \%$ and 37.15 $\%$, respectively. When the porousity of the material is large, the lower ability of material to resist the air combustion product fusion. This results in quick drying process in contrast to the small porousity of materials. This finding can be applied throughout the convective dehydration process accompanied by the forced draft, when the air and combustion product fusion is swept through the grain mass layer of kernels (Varnamkhasti et al., 2008).

\subsection{Angle of Repose}

Between Susu Thai, local Susu and local Siding cultivars, they show no remarkable contrast in the angle of repose. The corresponding mean value for Susu Thai, local Susu and local Siding cultivars were $40.08^{\circ}, 39.45^{\circ}$ and $38.85^{\circ}$, respectively. This angle is important for the design of processing, storage and conveying systems of particulate materials. 
Materials with low angle of repose are highly flowable and can be transported using gravitational force or a small energy (Teferra, 2019).

\section{Conclusion}

This study provides the required information on physical properties of local glutinous rice properties, which are local Susu and local Siding cultivars, which are useful for designing an intended major equipment used for rough rice processing. The physical properties of the same cultivar (Susu) showed no significant difference compared to the Siding cultivar. In terms of designing an equipment, Siding requires a larger silo than the Susu cultivar. Other than physical properties, mechanical, thermal and morphological properties can be determined to supply a justly comprehensive knowledge on design parameters involved in rice processing.

Acknowledgments: The authors express their deepest gratitude to the Universiti Putra Malaysia for providing the financial and technical support to conduct this research. Also to Lembaga Pertubuhan Peladang (LPP) dan Pertubuhan Peladang Kawasan (PPK) Langkawi for providing the local glutinous rice sample and expertise.

Conflicts of Interest: The authors declare no conflict of interest of the study.

\section{References:}

Food and Agriculture Organization of the United Nations. (2018). Fats and fatty acids in human nutrition.

Fraser, B. M., Verma, S. S., \& Muir, W. E. (1978). Some physical properties of fababeans. Journal of Agricultural Engineering Research, 23(1),53-57. https://doi.org/10.1016/0021-8634(78)90079-3

Husain, A. N. (2010). Quality parameters for Malaysian rice varieties. MARDI Research Bulletin, 320-332

IRRI International Rice Research Institute. (1980). Annual report for 1980. Los Banos, Laguna, Philippines.

Irtawange, S.V. (2000). The effect of accession on some physical and engineering properties of African yam bean. [Unpublished Ph.D. Thesis]. Department of Agricultural Engineering, University of Ibadan, Nigeria.

Jain, R. K. \& Bal, S. (1997). Properties of pearl millet. Journal of Agricultural Engineering Research, 66, 8591.

Luh, B. S., (1980). Rice: Production and utilization. West port, CT: AVI publishing company, Inc.

Mir, S. A., Bosco, S. J. D., \& Sunooj, K. V. (2013). Evaluation of physical properties of rice cultivars grown in the temperate region of India. International Food Research Journal, 20(4), 1521-1527.

Mohsenin, N.N. (2001). Physical properties of plant and grain ( $2^{\text {nd }}$ ed.). Gordon and Breach Science Publishers, New York.

Nalladulai, K., Alagusundaram, K., \& Gayathri, P., (2002). Airflow resistance of paddy and its byproducts. Biosystems Engineering, 831, 67-75. 
Singh, N., Sodhi, N. \& Kaur, M., et al. (2003). Physico-chemical, morphological, thermal, cooking and textural properties of chalky and translucent rice kernels. Food Chemistry, 82(3), 433-439. Doi: 10.1016/s0308-8146(03)00007-4

Singh, N., Kaur, L. \& Singh, S.N., et al. (2005). Physicochemical, cooking and textural properties of milled rice from different Indian rice cultivars. Food Chemistry, 89: 253-259.

Shittu, T. A., Olaniyi, M. B. \& Oyekanmi, A. A., et al. (2012). Physical and water absorption characteristics of some improved rice varieties. Food and Bioprocess Technology, 5(1), 298-309. https://doi.org/10.1007/s11947-009-0288-6

Tabatabaeefar, A. \& Rajabipour, A., (2005). Modeling the mass of apples by geometrical attributes. Scientia Horticulturae 105, 373-382.

Teferra, T. F. (2019). Engineering PROPERTIES OF FOOD MATERIALS. Handbook of farm, dairy and food machinery engineering, 45-89.

Varnamkhasti, M. G., Mobli, H. \& Jafari, A., et al. (2008). Some physical properties of rough rice (Oryza sativa 1.) grain. Journal of Cereal Science, 47 (3), 496-501. Doi:10.1016/j.jcs.2007.05.014

Copyright (C) 2021 by Zainal N, et al. and HH Publisher. This work is licensed under the Creative Commons Attribution-NonCommercial 4.0 International Lisence (CC-BY-NC4.0) 